\section{Net Pension Replacement Rates}

Pensions generally have the function to smooth consumption paths, to redistribute and to provide insurance against risks such as longevity. Against the backdrop of recent events such as the financial crisis, ageing demographics and low interest rates, a key question for individuals in developed countries is whether their pension is sufficient to maintain their previous standard of living.

\section{Facing demographic challenges}

Given the demographic changes in developed countries, the predominantly pay-as-you-go (PAYG) financed public pension systems in particular have come under considerable financial pressure in recent years. In PAYG financed systems no pension reserves for workers are set aside during their working time, but are directly transferred from younger workers' taxes to retirees. Demographic changes (lower birth rates and increased longevity) are reflected in a rising old age support ratio over the past decades. This ratio, which measures the number of people at working age relative to the number at retirement age, has declined from 6.6 in 1950 to 3.3 in 2013 in the EU, and is projected to fall to 1.8 workers per retiree by 2050 (OECD 2013). These issues have given rise to considerable worries over the financial sustainability of public pension systems, with most experts viewing a rise in contribution rates, a rise of the retirement age or a cut in benefits as inevitable solutions.

\section{Three pillar model}

To find adequate responses to the challenges mentioned above, the World Bank (1994) introduced the concept of the three pillar model. According to this model old age provisions are dividable into a publicly managed (first pillar), a mandatory private (second pillar) and a voluntary private system (third pillar). Moving away from an over-reliance on the first pillar and advocating a strengthening of the second pillar by diversifying into a mix of public and private pensions has been recommended by the World Bank as 'the best way to insure' against any uncertainties. Keeping a publicly managed pillar is seen as essential in order to maintain a redistributive function across society, while the second and third pillar are savings- and insurance-oriented only.
Other common arguments for keeping a public pension scheme include the potential shortsightedness of individuals (preventing them from saving anything at all), insurance market failures and information gaps.

\section{Net replacement rates}

The net pension replacement rate is an individual's net pension entitlement divided by net pre-retirement earnings. This rate shows how effectively each country's pension system provides a retirement income. In comparison to the gross replacement rate, taxes on both pensions and pre-retirement earnings have been accounted for already. Replacement rates can be further disaggregated according to income levels. In Table 1, low and high earners' entitlements are shown in addition to the mean entitlements (representing the entitlements of those with 0.5 and 1.5 times the average earnings). Following the structure of the three pillar model, pensioners' entitlements across Europe are compared in the form of the net replacement rate in Table 1 across 21 European countries in 2013, with the overall average net replacement rate for an average earner being 75.5 percent.

\section{Pillar compositions compared}

The average net replacement rate from public pensions alone was at 56.4 percent in 2013, while public and mandatory pension schemes taken together yielded an average net replacement rate of 67.5 percent. Comparing total mandatory net replacement rates across countries, the Netherlands provides the highest net replacement rate at 101.1 percent, while Ireland is at the lower end of pension provisions at 37.3 percent of pre-retirement earnings.

Contributions to pensioners' entitlements from each pillar vary highly with ten European countries relying solely on a public scheme, six providing pensions through public and private mandatory schemes and five countries relying upon both public and voluntary schemes. The average replacement rate for pensioners in countries relying on public and/or mandatory schemes is at around 74.1 percent. In Germany, the Czech Republic, Belgium, the UK and Ireland, a much smaller provision is given, with an average replacement rate of 46.3 percent. Within this group, Germany offers the highest public provision at 55.3 percent for median earners, while Ireland's public scheme provides just 37.3 percent. If voluntary pen- 
Table 1

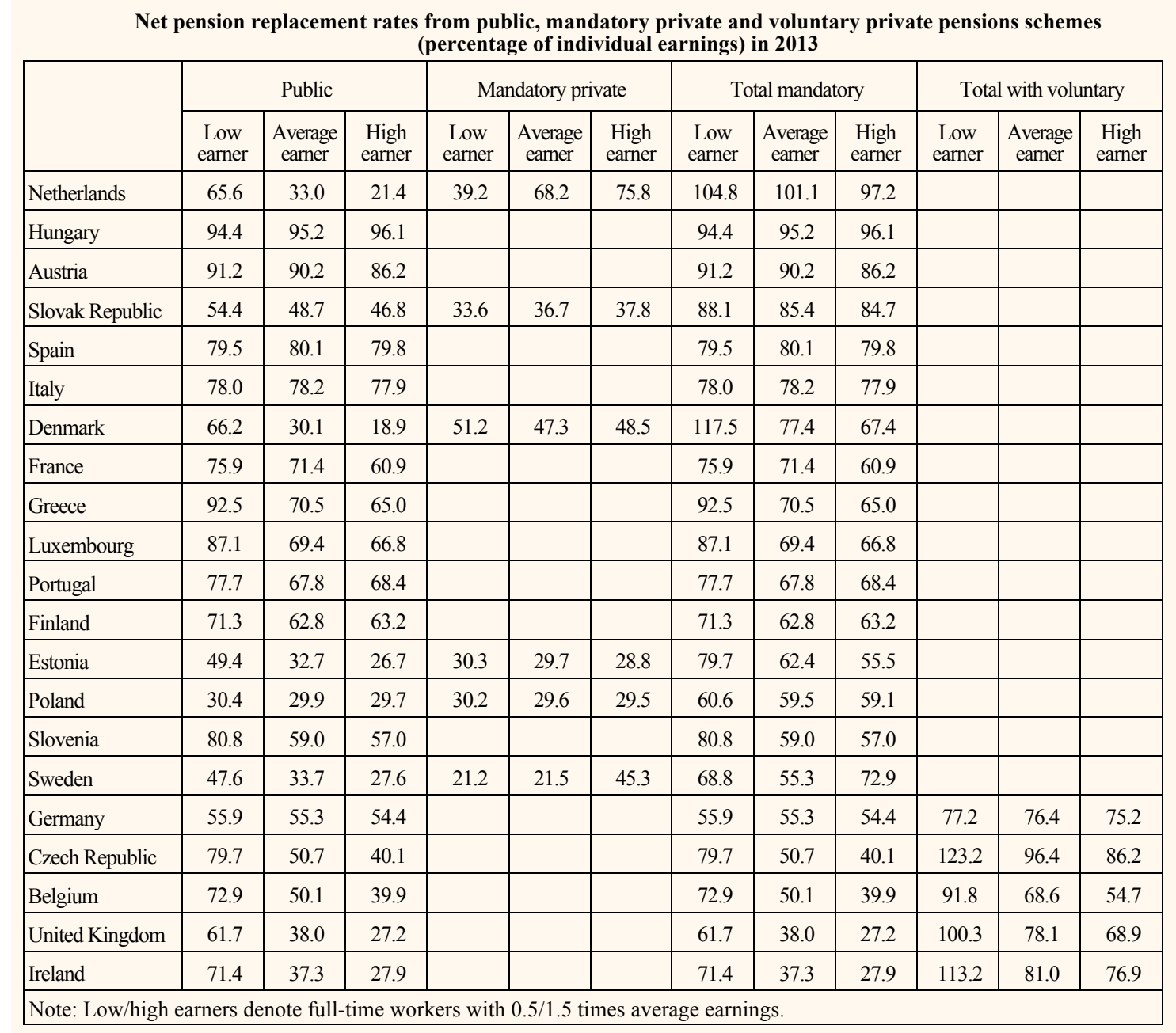

Source: Based on DICE Database (2015).

sion plans are taken into account, however, this group's average net replacement rate is 80.1 percent. Examining the coverage of private pension plans in these countries in 2011, Germany saw the highest coverage with 71.3 percent of the working age population, while voluntary pension schemes proved less common in the UK, with only 43.3 percent contributing to a private plan (OECD 2013).

\section{Replacement rates across earning groups}

Variations between net replacement rates are not only observable between countries, but also within each country across different earning groups. In 15 out of the 21 listed European countries net replacement rates decrease as earning increase, thus providing higher protection for the poorer (see Table 1). Differences in net replacement rates across earning groups are espe- cially pronounced in countries like Denmark, Greece, Luxembourg, Estonia, the Czech Republic, Belgium, the UK and Ireland, while differences in the Netherlands, the Slovak Republic, France, Poland and Germany are less pronounced.

\section{Comparison over time}

Comparing net replacement rates between 2005 and 2013 country by country reveals very different movements in replacement rates (see Figure 1). For 13 countries listed the net replacement rate for median earners decreased, while for the remaining six it increased. The largest decrease can be observed for Luxemburg, which moved from a net replacement rate of 110 percent in 2005 down to 69 percent. Greece experienced the second highest negative change, with its net replacement rate falling by over 29 percentage points. The most 
Figure 1

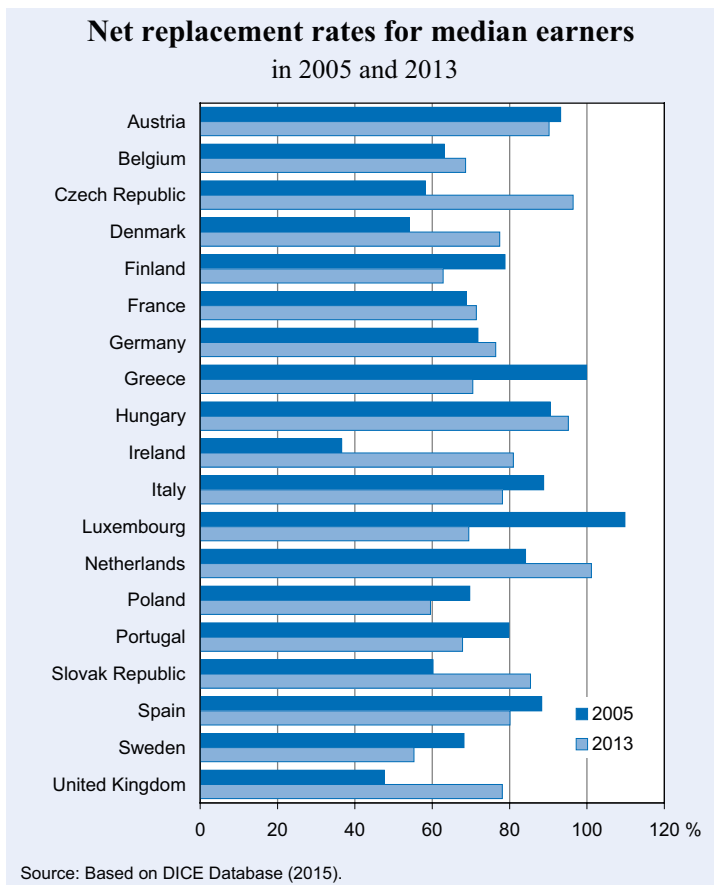

positive changes were seen for the Slovak Republic and Denmark, as their net replacement rates increased by 23 and 25 percentage points respectively.

\section{Concluding remarks}

Any definite answer to the question of what constitutes an 'adequate' public pension level remains subjective due to different living circumstances and expectations from country to country. The above comparison, however, indicates that additional private pension provisions in countries like Belgium, the UK, the Czech Republic, Ireland or Germany are more relevant and needed than in countries like the Netherlands or Austria, where the net replacement rates from mandatory pension schemes are already at a high level.

\section{References}

DICE Database (2015), "Gross / net pensions replacement rates from public, mandatory private and voluntary private pension schemes, 2005 - 2012", Ifo Institute, Munich, online available at http://www.cesifo-group.de/DICE/fb/3W8xJEqkP.

OECD (2013), Pensions at a Glance 2013: OECD and G20 Indicators, OECD Publishing, Paris. DOI: http://dx.doi.org/10.1787/ pension_glance-2013-en

World Bank (1994), Averting the old age crisis: policies to protect the old and promote growth, Washington DC, World Bank, http://documents.worldbank.org/curated/en/1994/09/698030/ averting-old-age-crisis-policies-protect-old-promote-growth.

\section{Kathrin Rochlitz}

